\title{
A aplicabilidade e eficácia das oficinas de pesquisa e produção textual na iniciação científica
}

\section{The applicability and effectiveness of the offices of research and textual production in scientific initiation}

La aplicabilidad y eficacia de las oficinas de investigación y producción textual en la iniciación científica

Bruna Gonçalves Xavier ${ }^{1}$ Arlinda Cantero Dorsa ${ }^{2}$

${ }^{1}$ Mestranda no Programa de Doutorado e Mestrado em Desenvolvimento Local em Contexto de Territorialidades, pela Universidade Católica Dom Bosco (UCDB). Cursando Especialização em Direito Penal e Processo Penal: Corrupção, Crime Organizado e Democracia, pela Escola de Direito da Associação dos Membros do Ministério Público (EDAMP). Graduada em Direito pela UCDB. Membro do Grupo de Pesquisa Patrimônio cultural, Direito e DiversidadeUCDB-MS. E-mail: bruna_xavier2@hotmail.com

${ }^{2}$ Doutora em Língua Portuguesa pela Pontifícia Universidade Católica de São

Paulo. Mestrado em Comunicação e Letras pela Universidade Presbiteriana Mackenzie. Graduação em Letras com Francês, pela Universidade Católica Dom Bosco, Graduação em Pedagogia pela Faculdade de Educação, Ciências e Letras de Urubupungá. Professora e pesquisadora da Universidade Católica Dom

Bosco, Coordenadora e Docente do Programa de Pós-Graduação Mestrado e Doutorado em Desenvolvimento Local. Docente do curso de Direito e de cursos de Pós-graduação lato sensu. E-mail: acdorsa@uol.com.br 
Resumo: Este artigo tem como foco a aplicabilidade e eficácia das oficinas de pesquisa e produção textual na iniciação científica em uma universidade privada confessional. Objetivou-se pesquisar o papel docente e discente nessas ações pedagógicas, norteado pelas seguintes problemáticas: Por que um número considerável de alunos encontra dificuldades na elaboração de textos científicos? Qual o papel dos docentes e discentes nesse contexto? Quais são as práticas textuais discursivas necessárias? Nesse contexto, é importante destacar a relevância do docente nas ações desenvolvidas frente aos alunos nas oficinas oferecidas, ainda que estes possam demonstrar dificuldades tanto na capacidade leitora como também na elaboração das produções textuais exigidas na iniciação científica. Dessa forma, foi possível obter resultados que nos demonstraram o motivo das dificuldades dos discentes e como podem dirimir esses obstáculos, bem como a importância das oficinas de pesquisa e produção textual na iniciação científica.

Palavras-chave: iniciação científica; oficinas textuais e formais; pesquisa.

\begin{abstract}
This article focuses on the applicability and effectiveness of textual research and production workshops in scientific initiation in a private, confessional university. The objective was to research the teaching and learning role in these pedagogical actions. Guided by the following issues: Why do many students find it difficult to write scientific texts? What is the role of teachers and students in this context? What are the necessary discursive textual practices? In this context, it is important to highlight the relevance of the teacher in the actions developed in front of the students in the offered workshops, even though these may demonstrate difficulties both in the reading capacity and in the elaboration of the textual productions required in the scientific initiation. In this way, it was possible to obtain results that showed us the reason for the difficulties of the students and how they can solve these obstacles, as well as the importance of the workshops of research and textual production in the scientific initiation.
\end{abstract}

Keywords: scientific initiation; textual and formal workshops; search.

Resumen: Este artículo tiene como foco la aplicabilidad y eficacia de los talleres de investigación y producción textual en la iniciación científica en una universidad privada confesional. Se objetivó investigar el papel docente y discente en estas acciones pedagógicas. Norteado por las siguientes problemáticas: ¿Por qué un número considerable de alumnos encuentra dificultades en la elaboración de textos científicos? ¿Cuál es el papel de los docentes y discentes en ese contexto? ¿Cuáles son las prácticas textuales discursivas necesarias? En este contexto, es importante destacar la relevancia del docente en las acciones desarrolladas frente a los alumnos en los talleres ofrecidos, aunque éstos puedan demostrar dificultades tanto en la capacidad lectora y también en la elaboración de las producciones textuales exigidas en la iniciación científica. De esta forma, fue posible obtener resultados que nos demostraron el motivo de las dificultades de los discentes y cómo pueden dirimir esos obstáculos, así como la importancia de los talleres de investigación y producción textual en la iniciación científica.

Palabras clave: iniciación científica; talleres textuales y formales; investigación. 


\section{INTRODUÇÃO}

A temática abordada neste artigo volta-se às oficinas de pesquisa e produção textual no que tange à sua aplicabilidade e eficácia na iniciação científica. A temática escolhida decorre da curiosidade acerca do assunto, uma vez que as oficinas textuais vêm contribuindo para sanar as dificuldades que os acadêmicos encontram ao ingressar na universidade e se depararem com graves problemas na construção de textos científicos exigidos ao longo da iniciação cientifica.

O referido trabalho teve como lócus de pesquisa uma universidade privada e confessional e tem como objetivo pesquisar o oferecimento, por parte de dois professores coordenadores de projeto de Iniciação Científica (IC) e professores pesquisadores colaboradores, de oficinas de pesquisa e elaboração do texto científico, abarcando as práticas discursivas dos acadêmicos em projetos de IC, partindo das dificuldades e possibilidades que os discentes encontram em suas práticas discursivas nos trabalhos desenvolvidos, bem como de estratégias textuais e formais que devem ser utilizadas.

A pesquisa é produto de uma discussão maior, relacionada ao projeto de pesquisa "Da elaboração do texto na universidade à divulgação científica: caminhos percorridos e a percorrer" e faz parte de uma discussão mais ampla, desenvolvida pelo "Grupo de Pesquisa em Patrimônio Cultural, Direitos e Diversidade", formado por professores-pesquisadores da Graduação e do Mestrado em Desenvolvimento Local, pós-graduandos/orientandos, acadêmicos em iniciação científica, com uma visão interdisciplinar, bem como pesquisadores ligados a outras instituições interessados em estudos e pesquisas desenvolvidas no âmbito do grupo acima citado.

Para a consecução dos objetivos, são tratados nesta pesquisa os seguintes assuntos: a iniciação científica, as oficinas de pesquisa em produção textual e o oferecimento de oficinas de pesquisa na referida universidade.

\section{DA INICIAÇÃO CIENTÍFICA}

A iniciação científica fomenta no orientando um sentimento de prestígio, ao fazer com que este visualize que o "mundo" da pesquisa não é restrito apenas a um grupo seleto de pesquisadores. Isso é importante, 
porque abre a possibilidade para que ele veja que também pode fazer parte da comunidade científica e obter consideráveis resultados a partir de sua dedicação, a ponto de ver seu trabalho reconhecido pelos seus pares e tido como útil para a sociedade.

Esses sentimentos e avanços promovem um estímulo, proporcionando que o orientando comece a traçar seus primeiros caminhos em um espaço até então desconhecido, fazendo com que se torne um sagaz pesquisador. A relevância da iniciação à pesquisa, conforme salienta Von Zuben (1990), consiste em possibilitar um olhar questionador, ao fazer com que os orientandos busquem compreender o autêntico sentido em fazer pesquisa e o seu papel no seio da academia.

Apesar da relevância em se fomentar a pesquisa científica na universidade, ainda prevalecem muitos desafios para sua efetiva concretização, seja pela disponibilidade dos docentes em orientar o processo, seja pelo interesse dos discentes em buscar se informar sobre ingresso e participação, ou ainda pela falta de incentivo para o desenvolvimento do trabalho por parte das instituições.

Sob essa perspectiva, ressalta-se que em muitos países, há anos, vem-se investindo nessa área e obtendo resultados, ao passo que no Brasil o incentivo à iniciação científica é algo recente. Sobre isso, Tenório e Beraldi (2010, p. 390) destacam os seguintes dados:

A história da iniciação científica no Brasil tem início em 1988, quando o CNPq (órgão federal criado 37 anos antes, em 1951) instituiu o PIBIC (Programa Institucional de Bolsas de Iniciação Científica). Antes disso, somente os pesquisadores tinham acesso às bolsas de estudo. Hoje, várias fundações de amparo à pesquisa, como FAPESP, FAPERJ e FAPEMIG incrementam o fomento à pesquisa nos seus respectivos Estados. A Iniciação Científica é, portanto, um projeto recente, mas que conta com uma considerável extensão pelo país: está implantada em 78\% das Instituições de Ensino Superior (IES) públicas e 71\% das particulares ${ }^{3}$. Contudo, quando a opinião dos alunos é analisada, surgem indícios de que ainda há grandes problemas a serem resolvidos, principalmente relacionados à distribuição de recursos financeiros e falta de institucionalização dessa atividade.

Dessa análise, verifica-se que, além dos desafios já apontados, os dados acima citados revelam que há ainda um entrave acerca da distribui- 
ção dos recursos financeiros de fomento à pesquisa e a falta de institucionalização dessa atividade, tendo em vista que muitos, apesar de sentirem o desejo de ingressarem na comunidade, não veem a oportunidade de concretizar suas pretensões.

Nesse diapasão, extrai-se a importância da superação desses obstáculos a fim de garantir a oportunidade de participação, bem como de recursos para desenvolvimento da pesquisa, em razão de que a iniciação científica é vista como um processo inicial de vinculação de um acadêmico de graduação com a prática científica, traduzindo assim, o significado de um conjunto de pessoas dedicadas a certas atividades científicas, as quais possuem regras e procedimentos, de modo que ingressar na pesquisa é poder compartilhar desse código de normas.

Frente a isso, o PIBIC-CNPq, em seu site institucional, menciona que, por meio da pesquisa, é possível introduzir os estudantes da graduação potencialmente promissores na pesquisa científica, caracterizando-se como instrumento de apoio teórico e metodológico à realização de um projeto de pesquisa, constituindo, assim, um canal adequado de auxílio para a formação de uma nova mentalidade no aluno.

Ainda de acordo com as normas do CNPq, disponíveis virtualmente, extrai-se que, por meio da iniciação à pesquisa, é possível desenvolver no aluno algumas das competências necessárias ao pesquisador, como a postura crítica, dedicação, criatividade, leitura científica, parcimônia, pensamento lógico, interesse pelo método científico (primeiro estágio), entre outros.

Nesse sentido, há ainda outras vantagens relativas à iniciação científica, como: desenvolver um projeto que responda a um questionamento seu; aprofundar-se no tema; participar de um grupo de pesquisa; formar-se como pesquisador; ter oportunidade de receber uma bolsa de estudos ou desenvolver pesquisa como pesquisador voluntário; participar de congressos e demais eventos científicos; receber menções honrosas, prêmios, currículo; ter sua pesquisa reconhecida e ser reconhecido; melhorar a sua formação na graduação; conhecer novas pessoas, trocar experiências, viajar, entre outros.

Nesse diapasão, defende Scorsolini-Comin (2014, p. 6):

A iniciação científica é um processo amplo que não abarca apenas o período no qual o aluno recebe uma bolsa de estudos. [...] Trata- 
se, portanto, de uma aproximação do aluno de graduação com o universo científico, uma espécie de primeiro estágio, de primeira experiência com uma área de conhecimento. A universidade é o espaço de formação e a iniciação é um dos programas desenvolvidos para que o aluno possa ter acesso à formação em pesquisa, podendo entrar em contato com orientadores, professores, pesquisadores e demais pessoas envolvidas no processo. Essas pessoas podem estar em laboratórios, centros de pesquisa, grupos de estudo ou em sala de aula.

Com base nisso, a relação do lócus pesquisado com a temática em questão demonstrou-se como de grande relevância; tendo em vista a análise do histórico da iniciação científica nessa instituição até os dias atuais, constata-se que houve uma grande evolução. Sendo que, em 1994, a universidade ingressou no Programa Institucional de Bolsas de IC do CNPq, recebendo 10 bolsas, contando com 10 planos de pesquisa e apenas dois professores titulados.

Em 1995, além das bolsas do referido programa foram acrescentadas mais seis, sendo três do CNPq e três da instituição participante desta pesquisa. No ano posterior, esse número foi ampliado para 20 bolsas da academia, trazendo à tona o reconhecimento da importância da IC na comunidade acadêmica.

Posteriormente, em 2001, a universidade encerrou o VII ciclo com 50 planos de pesquisa elaborados por 44 alunos bolsistas e 06 alunos voluntários e com 33 professores orientadores titulados. Em 2010, percebe-se nitidamente a evolução da pesquisa com a apresentação no encerramento do ciclo de 201 planos de trabalho, sendo que em 2013-2014, a universidade encerrou o PIBIC com a apresentação de 274 trabalhos.

Frente ao exposto, constata-se que, da implantação do sistema de bolsa, em 1994, até os dias atuais, foi percebida a importância da iniciação científica para a formação dos orientandos, pois é por meio desta que assuntos pouco abordados na educação base vêm à tona, fazendo com que eles desenvolvam suas habilidades ainda na graduação e encorajando-os nos caminhos da pesquisa científica. 


\section{DAS OFICINAS DE PESQUISA E PRODUÇÃO TEXTUAL}

Diante dessa análise acerca da iniciação científica e sua importância na academia, ressalta-se que muitos alunos, ao ingressarem nessa área, encontram dificuldades com a redação científica, tendo em vista as várias peculiaridades que a envolvem, além das próprias dificuldades nesse contato inicial com a comunidade científica.

Em razão disso, o oferecimento das oficinas de pesquisa e produção textual para os orientandos, e também ao público em geral, fortalece o compromisso da universidade em se destacar como um ambiente de produção do conhecimento, o qual, além de ensinar os conteúdos já previstos, fomenta uma nova perspectiva por meio de um olhar crítico e inovador.

Nesse sentido, as oficinas de pesquisa e produção textual oferecidas pelos professores da instituição podem proporcionar aos acadêmicos um elo com a comunidade científica, além de se revelar como um grande meio para que estes possam adquirir o aprendizado na elaboração do texto cientifico e outras competências.

Sob essa perspectiva, é importante destacar que os alunos, ao ingressarem na universidade, podem tomar um susto ao se depararem com a redação científica, pois, durante a sua educação base, não encontraram o incentivo necessário à sua elaboração, bem como há uma defasagem nessa esfera, pois, diante das várias interfaces dos gêneros textuais, apenas alguns destes são abordados durante os níveis de ensino. Isso, em parte, justifica essa dificuldade que os acadêmicos encontram ao se depararem com um artigo, por exemplo.

Nesse sentido, após considerar os entraves encontrados pelos discentes em seus primeiros contatos com esse ambiente, é relevante compreender o que seria esse texto científico. Segundo Silveira citada por Dorsa (2011), o texto científico seria um "discurso do saber", abarcando dois discursos produzidos em tempos diferentes, conforme palavras da autora:

O discurso da descoberta é do tipo narrativo, produzido solitariamente pelo cientista na busca da resolução de um enigma, a fim de tomar posse do "saber"; o discurso da manifestação é social, produzido para tornar conhecida à comunidade científica, a descoberta realizada 
pelo cientista, transmitindo, assim, o "saber" adquirido. (DORSA, 2011, p. 191).

Na construção do texto voltado à comunidade científica, existem normas preestabelecidas pela comunidade como sendo características necessárias, quais sejam: impessoalidade, objetividade, clareza, precisão, coerência, concisão e simplicidade.

Por conseguinte, essas oficinas pedagógicas vêm como uma forma de proporcionar ao acadêmico uma diversificação de novos aprendizados voltados ao conhecimento científico. Por exemplo, um aluno do primeiro semestre encontra-se em uma situação complicada, no início das aulas, quando seu professor pede-lhe que desenvolva um artigo sobre determinado tema.

O professor pressupõe que esse acadêmico saiba desenvolver tal gênero textual, contudo, na maioria dos casos, esse aluno se assusta, pois ainda não Ihe foi ensinado isso. Em outro contexto, este é convidado a ingressar na IC e se depara com outras situações textuais e formais que desconhece. Qual o melhor caminho? Sendo assim, as oficinas contribuem muito para o aprendizado dos acadêmicos, pois gradativamente esses discentes podem se apoderar desse conhecimento que Ihes trará inúmeros benefícios na produção textual e formal. Dentre estes, pode-se destacar:

1) Desenvolvimento de capacidades mais diferenciadas nas expressões orais e escrita e nas habilidades manuais: As referidas oficinas pedagógicas proporcionam também o desenvolvimento de algumas habilidades que, muitas vezes, não foram tão trabalhadas na educação base. Por exemplo, na comunicação oral de um banner, ou ainda, na elaboração de um artigo sendo que o acadêmico possuía dificuldade em desenvolver redações.

2) Os estudantes aprendem a ler bibliografia de forma crítica, uma vez que nas oficinas são evidenciadas por que, entre o texto " $A$ " e o " $B$ ", o " $B$ " é mais fundamentado que o " $A$ ", e quais as razões para isso: Fomenta no acadêmico um olhar crítico, contribuindo no desenvolvimento interpretativo dele.

3) Faz o acadêmico perder o medo de falar diante de plateias: Grande parte dos discentes possui certo temor de falar em público, talvez temendo as críticas ou por razões próprias. O fato é que, nessas oficinas pedagógicas, 
é possível torná-lo um orador em qualquer lugar, pois, ao apresentar seus trabalhos, este interage com os demais participantes e vê que pode ser reconhecido por isso.

4) O aluno aprende a ser autônomo apoiado na diretriz do orientador: Desde o inicio da vida estudantil, o acadêmico sempre esteve vinculado ao olhar de seu professor, por quem é dirigido. Nas oficinas textuais e na participação de um projeto de iniciação científica este aprende a seu autoprogramar e fazer suas atividades por conta própria, atuando o professor como um orientador, o qual the dá a direção, e não aquele que realiza o trabalho por ele.

5) Ao se deparar com uma dificuldade, passa a ter habilidade para interpretar e discernir se pode resolvê-la: Desenvolve técnicas interpretativas, bem como resolutivas de problemas, que antes poderiam parecer sem solução.

Urge destacar que é primordial na vida de qualquer profissional o bom desempenho de suas habilidades, sejam elas orais ou escritas na elaboração de documentos, principalmente em se tratando de operadores do direito, no que concerne à elaboração das peças, sustentações orais e interpretação.

Dessa forma, a realização das oficinas proporciona o amadurecimento do graduando, possibilitando a este uma familiarização com a elaboração do texto científico e principalmente na produção dos textos ligados a IC.

\section{DAS OFICINAS DE PESQUISA E PRODUÇÃO TEXTUAL OFERECIDAS}

Durante a realização deste trabalho, nos deparamos com duas situações: por um lado, pesquisar sobre as dificuldades dos acadêmicos para a produção dos diferentes gêneros textuais com enfoque nas oficinas de pesquisa e produção textual e, por outro, esta pesquisadora teve que voltar o olhar para si própria, uma vez que estaria realizando seu primeiro ciclo e ingressando num âmbito até então desconhecido - a comunidade científica.

Nesse seguimento, foram realizadas quatro oficinas pedagógicas, as quais trouxeram temas variados, sendo que a 1 a Oficina teve por temática a importância da leitura. Foram abordados os seguintes aspectos importantes 
sobre leitura: A leitura na universidade, desenvolvimento do olhar crítico frente ao texto e como utilizar a análise do discurso.

Na 2a Oficina tratou-se sobre o texto científico, a percepção da comunidade científica, explicando-se sucintamente sobre os gêneros textuais científicos, a sua utilização em diversos momentos da vida acadêmica, na graduação, (resumos, resenhas, apresentação de trabalhos) na IC (projeto, relatório e elaboração de artigo) e na conclusão de curso (a monografia).

Foi abordada também a distinção entre comunicação primária (trabalhos específicos realizados na universidade) e secundária, (os textos científicos destinados ao público leigo e que são publicados em revistas de divulgação científica).

Outro aspecto importante abordado foi a explicação sobre as sequências textuais (narrativas, explicativas, descritivas e argumentativas) salientando a professora ministrante que, ao longo dos diversos gêneros textuais utilizados na universidade, muitas vezes fazemos uso simultâneo de duas ou mais sequências.

Na terceira oficina, oportunizou-se aos alunos de iniciação recém-ingressantes a possibilidade de apresentar sua pesquisa em andamento no 1ำ congresso de Ensino, Pesquisa e Extensão - Saberes em Ação - promovido pela universidade pesquisada.

Sendo assim, foi feita uma explicação sucinta da forma de participar em um congresso com apresentação de trabalho assim como foram trabaIhadas as normas textuais, formais e comunicacionais para elaboração de slides para a apresentação oral. Dos participantes das oficinas (20 alunos), cerca de $80 \%$ participaram do evento.

$\mathrm{Na}$ 4a oficina, os professores trabalharam as diferentes formas de citação textual nos trabalhos científicos, dando enfoque à questão do plágio, evidenciando as dificuldades enfrentadas pelos alunos de IC e a importância em utilizá-las de forma correta.

Os professores, ao longo da pesquisa, resolveram ministrar individualmente aos seus orientandos as orientações específicas para a elaboração do relatório parcial, em razão das leituras particulares feitas pelos alunos como base do referencial teórico a ser apresentado no término do semestre. 
Ademais, no decurso desta pesquisa, foi aplicado um questionário/ entrevista para 24 discentes de IC de diferentes cursos, por meio de um contato presencial abordando as dificuldades e questões sobre sua participação na IC, diante disso foi possível obter os seguintes resultados:

i) Em resposta ao primeiro questionamento: “Qual o principal papel da universidade frente aos alunos na IC?", dos acadêmicos entrevistados, seis responderam que é dever da instituição oferecer subsídios e incentivos para a iniciação no âmbito científico, enquanto 15 responderam que a universidade prepara e dá apoio aos alunos de maneira teórica e metodologicamente para realização de um projeto de pesquisa, bem como três responderam que é introduzir os estudantes da graduação na pesquisa científica.

Gráfico 1 - Principal papel da universidade frente aos alunos de IC

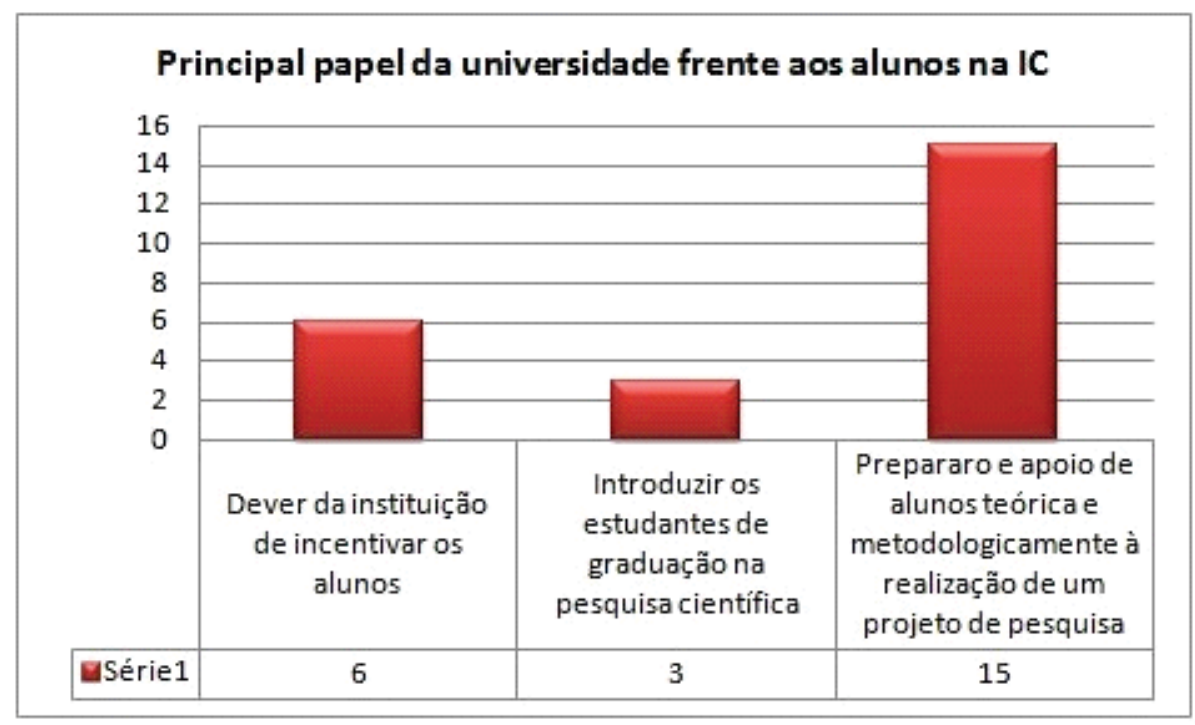

Fonte: Autoria própria.

b) O segundo questionamento foi: "Como o orientando chegou ao PIBIC?", sendo que 20 dos entrevistados informaram que o ingresso se deu por sua própria iniciativa, buscando um orientador, ao passo que 02 receberam convite do professor-orientador, e 02 por meio de indicação de um colega ou professor. 
Gráfico 2 - Como o orientando ingressou na IC

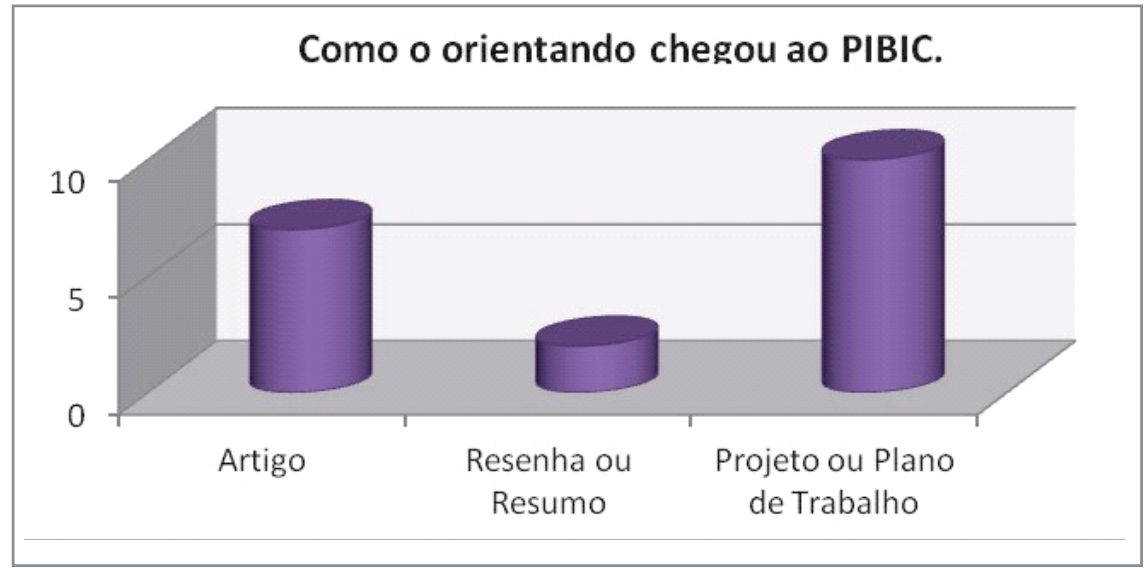

Fonte: Autoria própria.

c) No que tange à terceira pergunta, qual seja: "Quanto tempo participa do PIBIC?", 10 acadêmicos disseram ser este seu primeiro ciclo, enquanto 12 informaram estar no segundo ciclo e, apenas 01 está há mais de três ciclos.

Gráfico 3 - Tempo de participação na IC

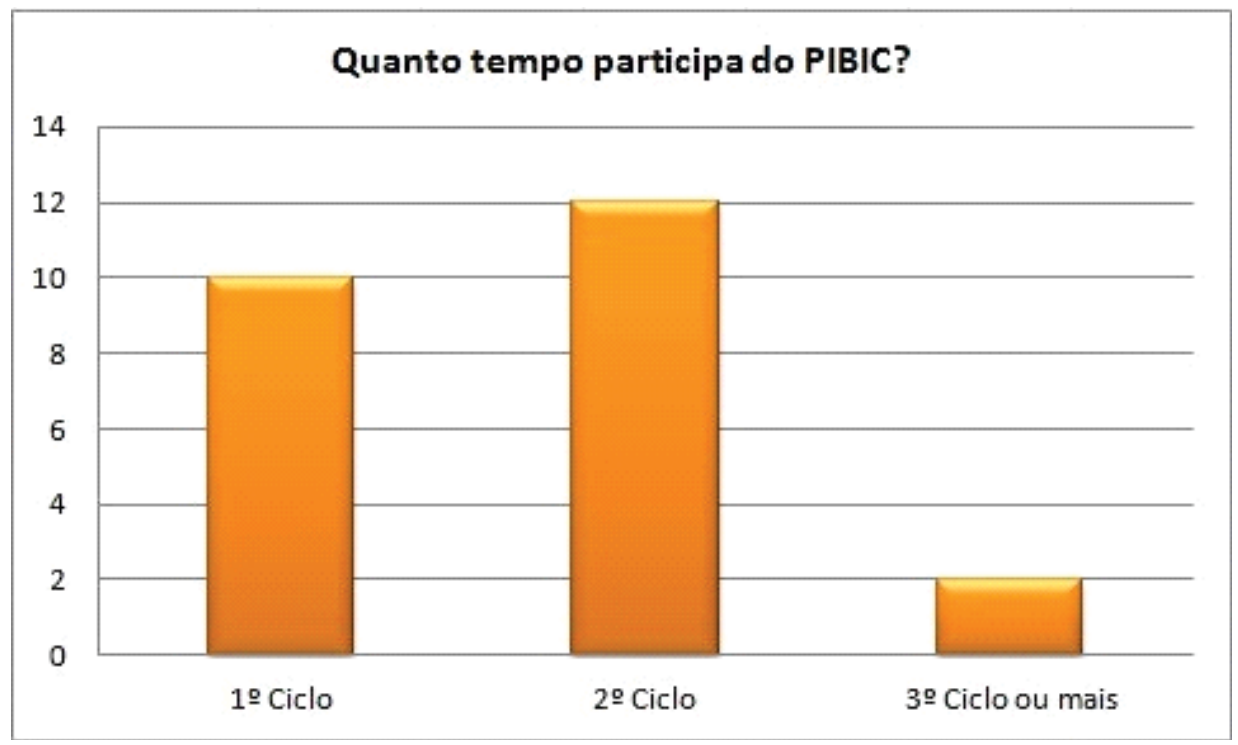

Fonte: Autoria própria. 
4) Em seguida, foi perguntado "Dentre os gêneros acadêmicos que já trabaIhou, em qual encontrou mais dificuldade?" sendo que 10 responderam ser no plano de trabalho, ao passo que 07 foi no artigo, 04 na elaboração de banners, 02 em resumos ou resenhas e, apenas 01 na comunicação oral.

Gráfico 4 - Gêneros textuais e a dificuldade dos acadêmicos

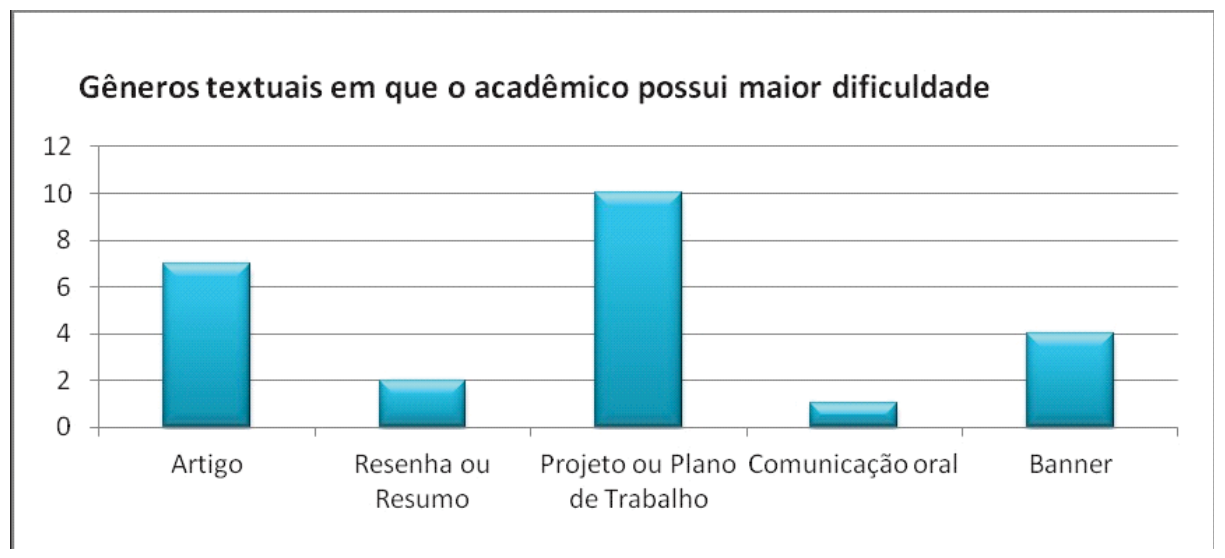

Fonte: Autoria própria.

5) Superada a fase de perguntas de ordem objetiva, foi disponibilizado um espaço para que o acadêmico respondesse, com suas palavras, ao seguinte questionamento: "Seu plano de trabalho foi desenvolvido por você? Você tem experiência com textos acadêmicos? Sabe elaborar um relatório, artigo científico ou outro?". E a grande parte dos entrevistados que estavam em seu primeiro ciclo responderam que a maior parte do plano de trabalho foi desenvolvida com o orientador, pois sentiram muita dificuldade em elaborá-lo. Para os que já participaram de ciclos anteriores, estes disseram terem eles mesmos elaborado. De igual forma, aqueles que estão iniciando disseram não ter experiência com textos acadêmicos, enquanto os demais afirmaram já saber desenvolver um relatório e o artigo, em razão dos ciclos anteriores em que participaram e aprenderam.

6) Na sequência, foi perguntado: "Qual a contribuição do professor-orientador na pesquisa?" A maior parte dos entrevistados disse que 
o seu orientador contribuiu de forma significativa para a realização do trabalho, enquanto a minoria respondeu que não houve tanta participação dele.

7) Por fim, indagou-se: "Qual a razão da sua participação na pesquisa científica? ", e a maioria relatou que era para adquirir aprendizado, enquanto outros visavam a fundamentos para elaborar a monografia e ter oportunidade de ingressar no mestrado.

Com relação à problemática apresentada " Por que um número considerável de alunos encontra dificuldades na elaboração de textos científicos?, Qual o verdadeiro papel dos docentes e discentes nesse contexto? Quais são as práticas textuais discursivas necessárias? Um número considerável de alunos, principalmente os oriundos de escola pública, ao ingressar no ensino superior, possui grande dificuldade na elaboração de textos científicos devido à falta de familiarização com esses gêneros textuais, uma vez que, na educação base, não lhes é cobrado e, poucas vezes, ensinado sobre o assunto, razão pela qual, ao se depararem com esses textos na universidade, se perdem e não conseguem desenvolvê-los.

Nesse diapasão, Simões (2002) aponta duas razões que levam o discente a enfrentar problemas na produção do texto acadêmico escrito: a falta de conhecimento linguístico e um quase total desconhecimento da forma que esse texto deve apresentar.

Consoante Oliveira (2009), esses alunos, ao ingressarem em universidades particulares, não conseguem acompanhar o "modelo autônomo de letramento", os quais deveriam ser desenvolvidos no ensino fundamental e médio. Nesse sentido, ressalta: "Não é possível considerá-los sujeitos 'iletrados', pois, em alguma medida, têm uma relação de uso com a escrita, só que voltada para as práticas escolares do ensino fundamental e médio, e não para atuar no contexto acadêmico".

Destarte, o modelo autônomo seria a capacidade da leitura e escrita desenvolvida na sala de aula, em que a primeira significa decodificar as palavras, e a última, ser capaz de codificar a língua dentro de uma forma visual, o texto (GEE apud OLIVEIRA, 2009, 121).

Nessa perspectiva, devido à defasagem do ensino base, o discente deve procurar se integrar sobre o tema, uma vez que será de grande impor- 
tância durante sua vida acadêmica, como na elaboração de sua monografia, bem como eventual prosseguimento nos estudos em uma especialização, mestrado ou doutorado, por exemplo.

Ramires (2007) sustenta que olhar para a comunidade acadêmica como sendo "monolítica" e "imutável" contribui para formar profissionais "reprodutores de discursos", os quais apenas refletem o que the foi passado na vida acadêmica, sendo incapazes de solucionar problemas sérios, como cidadãos na sociedade contemporânea.

Sendo assim, deverá o discente buscar bibliografias sobre o tema, bem como aproveitar das oficinas de pesquisa e produção textual oferecidas na universidade, podendo, inclusive, fazer parte de um grupo de pesquisa e se tornar um pesquisador. Nesse seguimento, o docente também possui um papel de grande importância no referido processo de aprendizagem, pois é ele que irá direcionar o discente e orientá-lo nos caminhos da comunidade científica.

É mister que o orientador seja participativo e colabore com o aprendizado e crescimento de seu orientando, de forma a encaminhá-lo, dando-Ihe autonomia e encorajando-o para fomentar neste o desejo de dar continuidade e contribuir para a pesquisa científica. A universidade também possui um papel muito importante, no sentido de garantir bolsas, incentivos, oferecer oficinas, materiais de pesquisa e proporcionar auxílio financeiro para viagens e despesas para apresentação das pesquisas em eventos desse fim.

Quanto às práticas discursivas necessárias, insta conceituar a palavra discurso, que para Maingueneau (1997) "etimologicamente significa ideia de curso, de movimento, palavra em movimento, prática de linguagem, constituindo o homem e sua história, mediadora entre o homem e a realidade que o envolve".

Dessa forma, é inegável que deverá se estabelecer um conjunto de ações e fatores para contribuir com o aprendizado por parte dos discentes e dos docentes, partindo, principalmente, dos primeiros, o anseio pelo conhecimento, sendo que as oficinas de pesquisa e produção textual se revelam como uma importante ferramenta para o desenvolvimento desse processo. 


\section{CONSIDERAÇÕES FINAIS}

Da análise do presente trabalho, é possível constatar que há uma considerável resistência por parte dos acadêmicos ao ingressarem na universidade em se interessarem pela iniciação científica, tendo em vista que encontram dificuldade com a redação e os gêneros textuais científicos.

Além disso, outro fator que se demonstra como um desafio é a escassez de docentes que se interessem em orientar os trabalhos e o apoio das instituições, além da questão de distribuição dos recursos para a pesquisa proveniente dos órgãos de fomento.

Ressalta-se a importância da IC para estimular várias habilidades no orientando, como desenvolver um olhar crítico frente ao que se deparar, bem como eliminar o medo de falar em público, trabalhando a oratória, em razão dos diversos eventos e apresentações de trabalhos, além do estímulo à autonomia, em que o discente realiza seu trabalho sem depender exclusivamente de seu professor, mas apenas com a orientação deste.

Acerca das oficinas de pesquisa e produção textual na universidade durante o correspondente ciclo, foram disponibilizadas oficinas para o estudo da leitura na academia, promovendo um debate sobre a necessidade de desenvolver no acadêmico um olhar crítico, bem como a análise do discurso.

Ademais, as outras oficinas versaram sobre os gêneros textuais científicos, posteriormente os orientandos que apresentariam trabalhos no congresso Saberes em Ação discorreram sobre suas pesquisas e, por fim, a última oficina tratou das citações textuais.

Outrossim, dos questionários aplicados, constatou-se que a maior parte dos orientados vê que o principal papel da instituição é disponibilizar o preparo técnico e metodológico, sendo que um maior número desses ingressaram na IC ao procurarem um orientador que pudesse auxiliá-los.

De igual forma, a maior parte dos entrevistados estavam em seu segundo ciclo e disseram que os gêneros textuais que consideravam mais complexos correspondiam ao plano de trabalho e ao artigo.

Diante do exposto, é inevitável ao discente encontrar dificuldades, contudo urge destacar que as oficinas trazem grandes resultados, conforme já exposto, para sanar tais obstáculos, bem como, com o devido apro- 
fundamento do acadêmico nos temas em questão, pode possibilitar-lhe o aprendizado e, consequentemente, um profundo desejo de angariar o título de pesquisador e ver seus trabalhos reconhecidos.

Conclui-se, ainda que parcialmente, que este trabalho expôs um conjunto de fatores que possibilitam a solução do problema levantado neste ciclo, o que não impede posteriores pesquisas sobre o tema, haja vista que o tema é atual e os resultados estão emergindo nas universidades e caminhando a passos largos desde 1988, quando o CNPq instituiu o $\mathrm{PIBIC}$, até os dias atuais com referencia ao incentivo voltado às iniciações científicas.

\section{REFERÊNCIAS}

DORSA, A. C. O texto científico e suas práticas discursivas na universidade: dificuldades e possibilidades. Anais do SILEL, Uberlândia, v. 2, n. 2, 2011.

MAINGUENEAU, D. Novas tendências em análise do discurso. 3. ed. Tradução de Freda Indursky. Campinas, SP: Pontes, 1997.

OLIVEIRA, E. F. Letramento Acadêmico: principais abordagens sobre a escrita dos alunos no ensino superior. In: ENCONTRO MEMORIAL - ICHS, 2., 11-13 nov. 2009, Mariana. Anais... Mariana: UFOP, 2009.

RAMIRES, V. Gêneros textuais e relações de poder na comunidade acadêmica. Revista do GEL, São Paulo, v. 4, n. 1, p. 129-47, 2007.

SCORSOLINI-COMIN, F. Guia de Orientação para Iniciação Científica. 1. ed. São Paulo: Atlas, 2014.

SIMÕES, D. M. P. A produção de textos acadêmicos. In: SIMÕES, D. M. P.; HENRIQUES, C. C. (Org.). A redação de trabalhos acadêmicos: teoria e prática. Rio de Janeiro: Ed. da UERJ, 2002.

TENORIO, M. P.; BERALDI, G. Iniciação científica no Brasil e nos cursos de medicina. Revista da Associação Medica Brasileira, São Paulo, v. 56, n. 4, 2010.

VON ZUBEN, N. A. A relevância da iniciação científica na universidade. Pro-posições, Campinas, v. 6, n. 2, p. 5-18, mar. 2016. 
